\title{
Developing the US Wildland Fire Decision Support System
}

\author{
Erin K. Noonan-Wright, ${ }^{1}$ Tonja S. Opperman, ${ }^{2}$ Mark A. Finney, ${ }^{3}$ G. Thomas Zimmerman, ${ }^{4}$ \\ Robert C. Seli, ${ }^{5}$ Lisa M. Elenz, ${ }^{4}$ David E. Calkin, ${ }^{6}$ and John R. Fiedler ${ }^{7}$
}

${ }^{1}$ Wildland Fire Management RDA, USDA Forest Service, 5765 Highway 10 West, Missoula, MT 59808, USA

${ }^{2}$ Wildland Fire Management RDA, USDA Forest Service, P.O. Box 5, Gardiner, MT 59030, USA

${ }^{3}$ Missoula Fire Sciences Laboratory, USDA Forest Service, 5775 Highway 10 West, Missoula, MT 59808, USA

${ }^{4}$ Wildland Fire Management RDA, USDA Forest Service, 3833 South Development Avenue, Boise, ID 83705-5354, USA

${ }^{5}$ Wildland Fire Management RDA, USDA Forest Service, 5775 Highway 10 West, Missoula, MT 59808, USA

${ }^{6}$ Missoula Forestry Sciences Lab, USDA Forest Service, 200 East Broadway, Missoula, MT 59807, USA

${ }^{7}$ IBM Global Services, 6300 Diagonal Highway, Boulder, CO 80301, USA

Correspondence should be addressed to Erin K. Noonan-Wright, enoonan02@fs.fed.us and Robert C. Seli, rseli@fs.fed.us

Received 24 December 2010; Accepted 3 March 2011

Academic Editor: Andrew Sullivan

Copyright ( 2011 Erin K. Noonan-Wright et al. This is an open access article distributed under the Creative Commons Attribution License, which permits unrestricted use, distribution, and reproduction in any medium, provided the original work is properly cited.

\begin{abstract}
A new decision support tool, the Wildland Fire Decision Support System (WFDSS) has been developed to support risk-informed decision-making for individual fires in the United States. WFDSS accesses national weather data and forecasts, fire behavior prediction, economic assessment, smoke management assessment, and landscape databases to efficiently formulate and apply information to the decision making process. Risk-informed decision-making is becoming increasingly important as a means of improving fire management and offers substantial opportunities to benefit natural and community resource protection, management response effectiveness, firefighter resource use and exposure, and, possibly, suppression costs. This paper reviews the development, structure, and function of WFDSS, and how it contributes to increased flexibility and agility in decision making, leading to improved fire management program effectiveness.
\end{abstract}

\section{Introduction}

Wildland fire in the United States carries the most risk and complexity of any discipline in natural resource management. During the last decade, managers have been faced with making increasingly complex decisions-trying to balance ecological objectives, public protection, and greater budget scrutiny. Examples include balancing ecological needs for fire in national parks (e.g., Yosemite National Park, California, USA), fuel hazard reduction benefits of wildfires, protection of the wildland urban interface, and air quality concerns in large urban areas (e.g., Southern California). While the total budgets for federal land management agencies have remained stagnant or decreased, fire-related expenditures for federal, state, and local entities have increased, reducing the proportion of funds available for achieving other land management responsibilities $[1,2]$. Additional factors such as changing fire, fuel, and human population dynamics; increasing diversity in land use objectives; and conflicting public views on costs and benefits of wildland fire have further increased the need for better, more informed management actions to address these complexities.

As decision complexity has increased, so too has the expectation that decisions will be transparent and communicated in a compressed time frame. To replace multiple processes developed by different agencies and reduce redundancy, senior fire leaders from all wildland fire management agencies concluded that a single decision analysis and documentation system was needed. This system had to be applicable to all wildland fires, regardless of objectives and situations. An effort was initiated in 2005 to develop such a system, named the Wildland Fire Decision Support System (WFDSS).

As a web-based system, WFDSS provides risk-informed decision logic and display capacity at multiple management levels. The components of risk analysis include access to 
TABLE 1: Administrative levels and spatial and temporal scales of the decision-making process in WFDSS.

\begin{tabular}{|c|c|c|c|c|}
\hline \multirow{2}{*}{ Administrative levels } & \multicolumn{2}{|c|}{ Scale } & \multirow{2}{*}{$\begin{array}{l}\text { Decision- } \\
\text { making } \\
\text { process }\end{array}$} & \multirow{2}{*}{ Description } \\
\hline & Temporal & Spatial & & \\
\hline Incident & Short (1-3 days) & Fine & Tactical & Specific actions related to managing an incident \\
\hline Incident & Short-long (3+days) & Fine-coarse & Strategic & Broader direction related to managing an incident \\
\hline Unit/region & Short-long & Coarse & Strategic & Strategic direction managing multiple fires \\
\hline National & Long & Coarse & Strategic & $\begin{array}{l}\text { Long-term strategic directions affecting large areas with } \\
\text { variable time frames }\end{array}$ \\
\hline
\end{tabular}

spatial data, fire modeling and computing resources, and economic valuation. Detailed risk assessments from WFDSS are readily accessible online to field users, analysts, and policy and decision makers at local, regional, and national levels. The process is linear, scalable, and responsive to changes in the fire situation (e.g., weather, values at risk, and fire fighting capacity). These attributes are important for accommodating a full range of management responses from immediate fire control to long-term management, or a combination of control, management, and monitoring strategies, for every ignition as outlined in the 2009 US federal fire management policy [3].

The objective of this paper is to review the US Wildland Fire Decision Support System. We begin by briefly discussing past and present US fire policy and the evolution of the decision-making environment in the context of wildland fire management. Next, we describe the design of WFDSS and how the system architecture assists with making a decision by encompassing a plethora of geospatial data and tools. We review WFDSS user statistics, the personnel who support its development and application, and demonstrate the utility of the system. To conclude, we discuss the projected future directions for WFDSS and the implications to fire managers.

\section{US Fire Policy and the Decision-Making Process}

Fire policy provides the overall framework for the fire management program, sets the basis for decision-making, and directly influences how, when, and why decisions are made. The US fire management program continues to escalate in complexity and risk due to many factors, including, increasing size and duration of fires; increasing importance of landscape values; decreasing levels of timber harvesting and resource utilization; altered fuel complexes and landscape structure; growing concern over short- and long-term ecological impacts of fires; emerging concern over possible effects of climate change; and increasing societal expectations regarding both management and protection. Response to these driving factors blended with innovations of science and technology and organizational learning strongly influence fire policy development. Recent policy modifications are emphasizing the importance of decisionmaking at all administrative levels and multiple scales.

2.1. Evolution of Fire Policy. Since its inception in the early 1900 s, wildland fire management has progressed from an informal program having a one-dimensional focus (fire control) to a sophisticated, multidimensional program faced with a full spectrum of protection and resource management objectives. For all decisions, US federal fire policy has required documentation, analysis, and reporting when (1) a wildland fire escapes or is expected to exceed initial fire suppression actions, (2) a wildland fire is managed for resource benefits, or (3) a prescribed fire exceeds its prescription and is declared a wildfire. However, each of these fire situations required different kinds of documentation and analysis. Changes to the federal wildland fire policy in 1995 made the requirements even more complex by allowing managers the latitude to choose from a full range of responses when faced with an unplanned ignition [4]. Federal fire policy was clarified for purpose and intent in 2001 and 2009 to emphasize collaboration amongst all the US federal land and fire management agencies [3, 5]. Revised policy implementation guidance in 2009 advised that all wildland fires utilize a single decision support process for every fire [3], and the National Wildfire Coordination Group (NWCG) suggested WFDSS be used for this purpose [6]. The policy permits the use of options ranging from traditional suppression to monitoring for each local management unit that has approved guidance in its land and resource management plan. This includes the ability to manage a single fire with multiple objectives. Fire suppression tactics may be applied on flanks with threatened infrastructure concurrently with monitoring engaged in areas where the same fire is a desirable landscape process. However, this policy also specifies that every unplanned human-caused ignition (e.g., arson, accidents, etc.) can only receive a suppression response. Ignitions from this source cannot be managed for resource benefits.

2.2. Decision-Making at Multiple Scales. In the US, fire decision-making occurs at multiple administrative levels and spatial and temporal scales (Table 1). At all scales, decision support tools must be available in real-time when managers are faced with making risk-based decisions. WFDSS allows authorized users to access all of the various administrative levels. Further, the system adapts as fires progress in time and space, guiding both tactical and strategic decision-making processes.

Incident-level decisions follow both a tactical and strategic process. Tactical decisions relate to specific actions occurring on a fire incident such as deploying and directing fire resources. Incident-level decision-making initially occurs 
over shorter time scales and finer spatial scales that are largely concerned with understanding the present situation. As the incident progresses in both time and space, incident-level decision-making considers broader objectives specific to a fire incident called strategic direction. The strategic direction process at an incident-level involves a broader-scale analysis that evaluates specific concerns for values (e.g., communities, water and air quality, habitat, resource management objectives); fire environment hazards (e.g., weather, fuels, and topography); and the probability of positive and negative impacts to the various values. Decision support applicable at this level may trend to longer time periods and coarser spatial scales, requiring more quantitative information about risk and potential outcomes.

When there are multiple fires at the unit or regional level, strategic decision-making encompasses much broader issues. At regional scales, decision support includes long-term situational products and fire behavior projections to assess threats to values and demand for fire suppression resources. WFDSS can be used to view locations of multiple incidents, weather or fire danger forecasts, analysis products, and decision documentation describing the chosen strategic direction.

At the national level, decision-making involves long-term strategic decisions affecting large areas, seldom focusing on an individual incident. Decisions are made by regional coordination groups or a federal administrator at a centralized office. National-level decision-making focuses on fire activity effects on resource availability, incident prioritization, and resource allocation. WFDSS allows access to all incident locations, risk-based assessments, and published decisions occurring across the country, facilitating a national perspective on the current fire situation.

2.3. Creating a New Decision Support System. In June of 2005, the National Fire and Aviation Executive Board (NFAEB) chartered the development of WFDSS [7] to replace several existing wildland fire decision processes with a single scalable decision support system. This new process was intended for incident managers to create and publish a wildland fire decision consistent with local land and resource management plans. Design criteria included (1) using the internet (webbased thin client implementation) for rapid sharing of information, (2) developing an enterprise application based on a service-oriented architecture (SOA), (3) incorporating economic principles and fire behavior modeling into the decision process, and (4) displaying geospatial information.

The development of WFDSS consolidated the previously separate fire management processes, fire modeling systems, data, and economic principles into one web-based location. Before WFDSS, multiple, agency-specific documentation methods were used for various types of wildland fires. The wildland fire situation analysis (WFSA) documented wildland fires that escaped initial suppression actions or were converted from a resource benefit or prescribed fire to a wildfire. Resource benefit fires were documented using a wildland fire implementation plan (WFIP). Producing WFSA and WFIP documents required a desktop software application, printing, and signature of the approving official. A long-term implementation plan (LTIP) or a strategic implementation plan (SIP) was sometimes developed locally for long-duration wildland fires, and used in conjunction with a WFSA or WFIP. Land management agencies often employed their own versions of these documentation methods. The fire decision process was complicated by the use of paper maps and lengthy land, resource, and fire management plans that were difficult to access. Consequently, consolidating nationally consistent wildland fire management data across different time and spatial scales and agencies was challenging.

The design of WFDSS improved upon existing documentation systems and made the wildland fire decision process accessible, consistent, flexible, and geospatial. Accessibility to thousands of users is ensured through a web-based system, where authorized users require only an internet connection and logon for access to the system, alleviating the need for updating desktop programs and acquiring large datasets. Consistency of both inputs and outputs is ensured by design. Incident information, analyses, and text are entered while outputs produced in WFDSS improve the ability of fire managers to quickly focus on pertinent information. The inclusion of the most up-to-date fire spread and economic sciences is embedded in the design of WFDSS. Research personnel working in conjunction with fire professionals develop and support the addition of new research concepts into WFDSS. Maps and other spatial information of values, assets, and the fire environment also contribute to the synthesis of information (Figure 1). Collectively, these improvements enhance the guiding principles of WFDSS, consolidating legacy methods with a single process that is intuitive and easy to use.

2.4. The Fire Decision-Making Process. Decision-making on fires in the US includes pre-ignition planning, publishing a decision, and continual reassessment. The temporal and spatial scales of these processes vary with the fire complexity.

2.4.1. Pre-Ignition Planning. Wildland fire management begins with planning prior to a fire response. US federal fire policy mandates that every unplanned wildland ignition receives a response developed from a full range of strategies. Each land management unit creates fire planning documents that may be more restrictive depending on local issues. All federal land management agencies create and follow a public-reviewed, comprehensive plan called a land and resource management plan (LRMP) to manage natural resources. Fire management plans (FMPs) are derived from the LRMPs to define fire management objectives for a local unit, address strategies and tactics, and describe the overall program of managing wildland and prescribed fires. Given the political, historical, environmental, and socioeconomic consensus, LRMPs and FMPs determine different fire zones where fires are managed (allowed to burn) for ecological benefit (resource benefit) or suppressed. Units with extensive wilderness areas tend to have a large zone where fires are managed for resource benefit and monitored with a pointprotection strategy to defend remote values (e.g., cabins, radio towers). Conversely, units with a small land base near urban developments will typically have a full suppression 


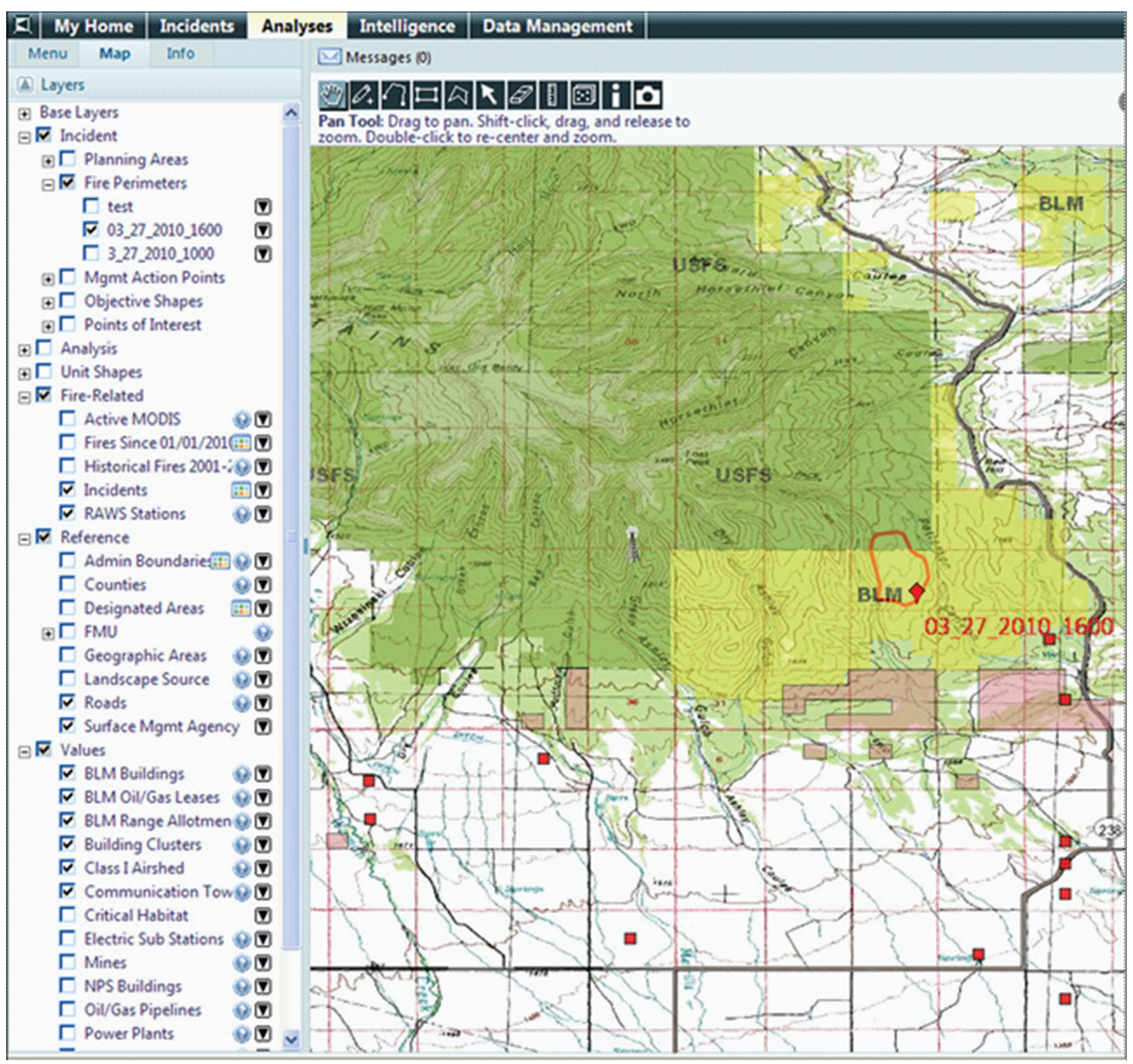

FIGURE 1: Geospatial data provided by WFDSS including information about fire location and size, reference information, and values. Geospatial layers with a check mark are viewable on the map. The red line is the fire perimeter from March 27, 2010 at 1600; small boxes represent Bureau of Land Management (BLM) buildings, USDA Forest Service (USFS) buildings, and building clusters; square polygons represent grazing areas for livestock (BLM range allotments). The BLM and USFS are the surface management agencies responsible for land management in their respective polygons.

strategy involving an immediate commitment of suppression resources upon fire discovery. This preplanned strategy influences decision-making and implementation of management actions once an ignition occurs. Prior to the fire season, local units upload georeferenced polygons of designated fire zones into WFDSS to display where fires can be managed, given the strategy and constraints for these areas.

2.4.2. Assessing the Fire Situation. Once a wildland fire starts, a cyclical process of assessment, risk-characterization, analysis, and deliberation begins in order to make a risk-informed decision. During the initial fire response, fire dispatchers and managers use WFDSS to assess the basic fire situation with a variety of assessment tools. Current weather observations, fire danger, and fuel moisture are retrieved from weather stations and National Weather Service forecasts. Maps of forest, brush, and grass fuel types with other geospatial data such as values at risk (infrastructure and natural resources) are viewable and applied with fire behavior and smoke modeling tools to determine the preliminary risk. Other assessment information available at this initial phase includes local, regional, and national fire situations; a quick, qualitative risk assessment; and the preplanned strategy defined in the FMP. All of this information can be communicated to firefighters prior to their arrival to the fire, and be used to develop strategy and tactics at this initial stage. If the preplanned strategy is accomplished, no further documentation is needed in WFDSS. For example, if a fire in a "suppression zone" is extinguished quickly, as outlined in the fire management plan, the response has followed a preplanned strategy. However, once it is clear that the fire will not be quickly extinguished, managers undertake additional 


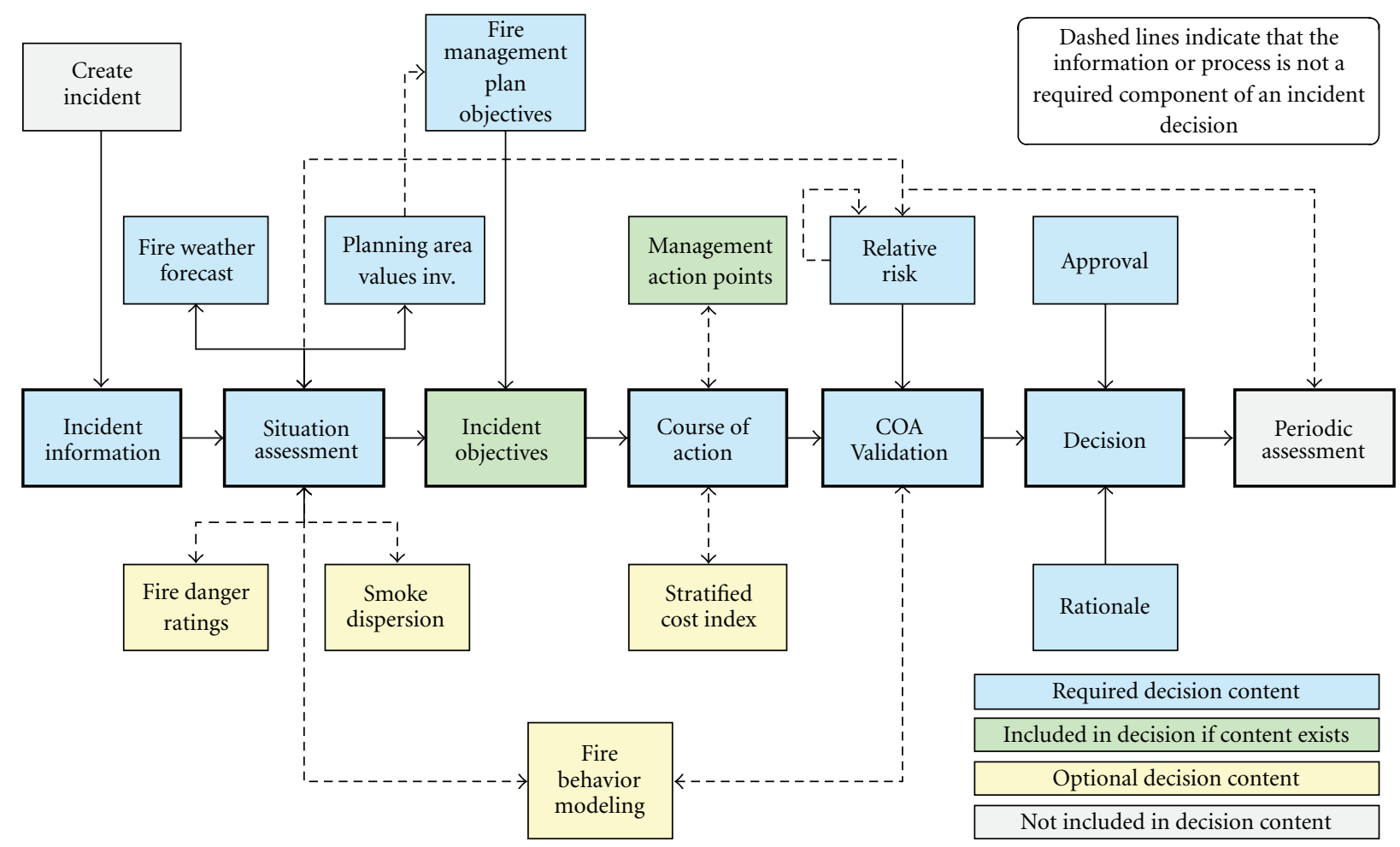

FIGURE 2: WFDSS conceptual model. The highlighted bolded horizontal flow depicts the major phases necessary to make a decision in WFDSS.

planning and analysis to further assess the situation and determine a different strategy. If a new strategy is developed, managers proceed through the WFDSS decision documentation (Figure 2), and eventually publish a new decision.

2.4.3. Documenting a Decision in WFDSS. Documenting a decision requires entering basic fire information, assessing the fire situation, estimating relative risk, identifying objectives, developing a course of action, publishing a decision and reviewing it for currency. The decision support structure in WFDSS is linear and includes seven different "phases" that guide a fire manager to develop a decision (Figure 2).

A new fire start is recorded using the Incident Information page. Location, size, date, and the agency responsible for the fire are documented here for administrative fire reporting purposes. The next step, Situation Assessment, provides maps, reference data layers, and applicable fire behavior and economic assessments to support the development of objectives specific for the emerging fire. Cost estimations, values, fire potential, hazards, and the situational assessment determine the relative risk for the emerging incident. If fire complexity is high or escalates, managers can use the risk assessment process to obtain a complete overview of the fire situation to better frame their decisions. The Incident Objectives page automatically populates preloaded, spatially relevant, fire management objectives as stated in land, resource, and fire management plans, to guide the development of incident objectives to manage the fire. On the Course of Action page (COA), managers define actions to meet specific incident objectives. A manager could delineate actual locations of contingency planning or actions to manage the fire using the geospatial data and maps. In summary, the strategy, costs, and resources necessary to manage the fire are described here. The COA Validation page provides an opportunity to review the Situation Assessment, Incident Objectives, and Course of Action to ensure that the objectives and associated actions are attainable and comply with LRMP/FMP guidance. If they cannot be met, the COA Validation page guides the development of a new course of action. Decision makers develop the decision documentation in a collaborative environment using information from both WFDSS and outside sources on the Decision page. A decision maker documents rationale for the decision, stipulates a timeframe for reassessing the decision, and approves the decision with an electronic signature. Finally, the Periodic Assessment page provides a process for a recurring review of the current decision to evaluate the effectiveness of chosen strategies and tactics, and, if warranted, initiate a new decision. These steps provide a scalable and consistent process to make a decision on a wildland fire incident.

\section{WFDSS Data and Tools}

Basic data services such as geospatial layers, tabular data, and point-based graphics coupled with fire behavior, economic, and air quality tools, are incorporated within the system architecture to provide fire managers with optimal information during the decision-making process. 
3.1. Geospatial Data. A variety of geospatial layers are available (Table 2), ranging from a local to national extent. Some layers are used internally but most layers can be displayed on WFDSS map pages by simply toggling layers on or off (Figure 1). Portions of many layers can be downloaded from WFDSS for use in other applications. National layers are from a variety of federal sources such as the Department of Homeland Security, the National Weather Service, and the Environmental Protection Agency. Examples include topographic maps and seamless surface and canopy fuels data [8]. WFDSS system administrators update these data annually. Regional Layers are an accumulation of local and regional data from different sources assembled into a single geospatial layer. Examples include locations of designated wilderness areas or critical habitat. These data undergo constant revision and are updated several times a year by a national cadre working with all agencies. Finally, local or incident-level layers are created and maintained by individual WFDSS users and linked to a specific incident. These data are maintained by individual users, updated continuously, and can be uploaded in the shapefile format or hand drawn within the WFDSS map page interface.

3.2. Tabular Data. Significant categories of tabular data are utilized in WFDSS. The largest is the historic Weather Information Management System (WIMS) data storing hourly remote automated weather station (RAWS) observations, which are used to create fire danger products and historic weather for fire behavior analyses. Fire management objectives and requirements from local fire management plans (see Section 2.4.1) can be entered by fire managers and linked to the fire management unit (FMU) geospatial layer, providing an accessible overview of strategic direction when fires start. Because WFDSS is used in real-time support of fires, tabular information can also provide information for individual fires and regional or national summaries.

3.3. Point-Based Graphics. Point-based graphics are available on the WFDSS maps page. Current, on-site weather observations associated with the closest RAWS are linked directly to a site hosted by the National Weather Service. An additional link provides fire weather forecasting information for a larger area surrounding the fire. Fire danger is displayed for the current fire season along with a forecast for the next seven days, overlaid on a composite graph representing the last 10 years of fire danger. This graphic provides a climatological context for the current fire situation using the Energy Release Component (ERC) of the US National Fire Danger Rating System, which reflects fuel moisture changes to dead and live fuel components [9].

3.4. Tools. Models and tools for analyzing fire behavior, economic, and air quality impacts are included in WFDSS. Fire behavior modeling systems are used to determine fire size probabilities, make fire progression forecasts, and predict fire behavior characteristics such as rate of spread, crown or surface fire occurrence, and fire intensity. Economic tools provide information on historical costs of past wildland fires burning under similar conditions, tabular displays of economic values at risk, and a risk assessment of important values overlaid on a fire spread probability map. Air quality tools provide information on possible smoke trajectories and smoke impacts. Collectively, these tools aid decision makers in making deliberative, risk-informed decisions on how to manage wildland fires.

3.4.1. Fire Behavior. A variety of fire behavior tools are available for analysis of short- and long-term WFDSS decisions. Fire behavior calculations estimate the spread and intensity of surface fire [10], crown fire [11, 12], and spotting distances from torching trees [13]. These calculations are implemented in several spatial tools depending on the duration and kind of information needed for the analysis (Figure 3). All products are processed on remote computers and the results displayed in the client's browser (see Section 4).

For short-term situations (e.g., up to one week), suitable analyses include (1) basic fire behavior characteristics of the flaming front (e.g., spread rate and flame length) for all cells across the entire landscapev based on forecasted weather (referred to as basic fire behavior), (2) fire growth simulation for a particular ignition source and forecasted weather using the minimum travel time method [14] (referred to as short term fire behavior), and (3) fire growth simulation up to 7 days using hourly forecasted weather [15] (referred to as near-term fire behavior). Short-term fire behavior shown in Figure 3(a) displays contours of fire progression as well as major fire travel routes.

Long-term fire behavior calculations address fire growth and impacts beyond the time frame of reliable weather forecasts. They are represented as probabilities because they are obtained from ensemble fire growth simulations [16] assuming an absence of suppression effects on fire perimeter growth. The fire spread probability simulator (FSPro) that was used to produce these probabilities, requires thousands of fire growth realizations. Starting from the current active fire perimeter, different potential weather sequences produce a single display showing spread probabilities as colored bands across the landscape. These weather sequences are produced by analyzing historical observations from a proximal weather station using an autoregression or time-series analysis of the energy release component (ERC). Because the ERC reflects fuel moisture changes to all dead and live fuel components, it displays significant autocorrelation out to 30 or 40 days. The time-series analysis combines the influence of observed ERC values (in the current season prior to the simulation) with forecasted ERC trends over the next several days to produce the autoregressive modeled sequences out to 14 days or more into the future [16]. The fire behavior for each day in the simulation is driven by combinations of fuel moisture from the daily ERC values and wind velocities that are stochastically sampled from the historical weather records for the simulation time period. Ensemble fire growth outputs include fire size distributions, burn probabilities, fire arrival day distributions, and conditional fire behavior distributions (scaled to sum to 1.0). Figure 3(b) illustrates FSPro ensemble burn probabilities for a 14-day simulation 
TABLE 2: Geospatial data layers in WFDSS. Available geospatial data layers range from national to local scales and include base layers, fuels, administrative references, values (natural resources and infrastructure), user-specified, and fire-related data. Examples of each category are provided with a short description. Extent refers to the spatial scale of the data set.

\begin{tabular}{|c|c|c|c|}
\hline Categories & Example layers & Extent & Description \\
\hline \multirow{2}{*}{ Base layers } & Topographic & National & Topographic maps at various scales depending on the zoom level \\
\hline & Google Products & National & $\begin{array}{l}\text { Google Physical and Maps showing shaded relief or remotely sensed } \\
\text { imagery }\end{array}$ \\
\hline Fuels & LANDFIRE & National & $\begin{array}{l}\text { Continuous, national-scale coverage of surface and canopy fuels and } \\
\text { elevation, slope, and aspect used for the fire behavior analyses }\end{array}$ \\
\hline \multirow{8}{*}{$\begin{array}{l}\text { Administrative } \\
\text { references }\end{array}$} & Counties & National & County boundaries within states of the US \\
\hline & Designated areas & Regional & $\begin{array}{l}\text { Federal government areas with a special designation, such as, } \\
\text { wilderness areas, research areas }\end{array}$ \\
\hline & Major roads & National & US interstate, highway, and major streets \\
\hline & Administrative boundaries & National & Proclaimed federal agency boundaries in the US \\
\hline & FMU data layer & Regional & $\begin{array}{l}\text { Fire management unit (FMU) areas from the land/resource/fire } \\
\text { management plans of the local field unit }\end{array}$ \\
\hline & Geographic Area Boundary & National & $\begin{array}{l}\text { Boundaries of the geographic areas, interagency regions for } \\
\text { mobilization of fire-fighting resources }\end{array}$ \\
\hline & Responsible agency & Regional & State or federal agency responsible for fire suppression \\
\hline & Surface management agency & Regional & Federal agency that manages land resources for a particular area \\
\hline \multirow{5}{*}{$\begin{array}{l}\text { Values-natural } \\
\text { resources }\end{array}$} & Sage grouse key habitat & Regional & Sage grouse areas (potentially a federally protected species) \\
\hline & Class I airshed boundary & National & Areas of federally protected air quality in the US \\
\hline & $\begin{array}{l}\text { Ozone and particulate } \\
\text { nonattainment areas }\end{array}$ & National & Areas where existing air pollution exceeds standards \\
\hline & Range allotments & Regional & Pastures and allotments for livestock grazing \\
\hline & Critical habitat & Regional & Critical habitat for Threatened and Endangered species \\
\hline \multirow{7}{*}{ Values-infrastructure } & Oil and gas leases & Regional & Oil and gas agreements and leases on federal lands \\
\hline & Federal buildings & Regional & All structures on federally managed lands \\
\hline & Building clusters & Regional & $\begin{array}{l}\text { County records of structures, representing one or more buildings or } \\
\text { homes }\end{array}$ \\
\hline & Communication towers & National & $\begin{array}{l}\text { Communication points recognized by the federal regulating } \\
\text { communications agency (FCC) }\end{array}$ \\
\hline & Mines layer & National & Locations of mines on federal lands \\
\hline & Distribution lines & National & Pipelines of oil, natural gas, and power transmission lines \\
\hline & Power stations and plants & National & Electric substations (subsidiary electric stations) and power plants \\
\hline \multirow{3}{*}{$\begin{array}{l}\text { User-specified, } \\
\text { incident and analysis }\end{array}$} & Fire perimeters & Local & $\begin{array}{l}\text { Fire perimeters obtained on the fire with any collection method. } \\
\text { Can be uploaded or hand drawn on the WFDSS map pages }\end{array}$ \\
\hline & Planning features & Local & $\begin{array}{l}\text { Points, lines, or polygons that will affect management decisions (i.e., } \\
\text { fuel treatments, cultural sites) }\end{array}$ \\
\hline & Analysis features & Local & $\begin{array}{l}\text { Fire ignitions, barriers to fire growth, or masks where fuel model } \\
\text { changes occur }\end{array}$ \\
\hline \multirow{6}{*}{$\begin{array}{l}\text { Fire-related } \\
\text { intelligence }\end{array}$} & RAWS stations & National & $\begin{array}{l}\text { Remote automated weather station locations with links to current } \\
\text { observations }\end{array}$ \\
\hline & $\begin{array}{l}\text { National digital forecast } \\
\text { database }\end{array}$ & National & $\begin{array}{l}\text { Five km grid of the national seven day weather forecast updated } \\
\text { hourly; used for fire danger products and fire behavior analyses }\end{array}$ \\
\hline & Historic fire perimeters & Regional & $\begin{array}{l}\text { US fire perimeters larger than } 40.5 \text { ha from } 2000-2010 \text {, including } \\
\text { Hawaii and Alaska }\end{array}$ \\
\hline & Current year fire perimeters & WFDSS & $\begin{array}{l}\text { Aggregate of the most current individual fire perimeters contained } \\
\text { in WFDSS }\end{array}$ \\
\hline & Active MODIS & National & $\begin{array}{l}\text { Remotely sensed infrared signatures updated twice daily at } 1 \mathrm{~km} \\
\text { resolution }\end{array}$ \\
\hline & Incidents & WFDSS & Location of fire incidents contained within WFDSS \\
\hline
\end{tabular}



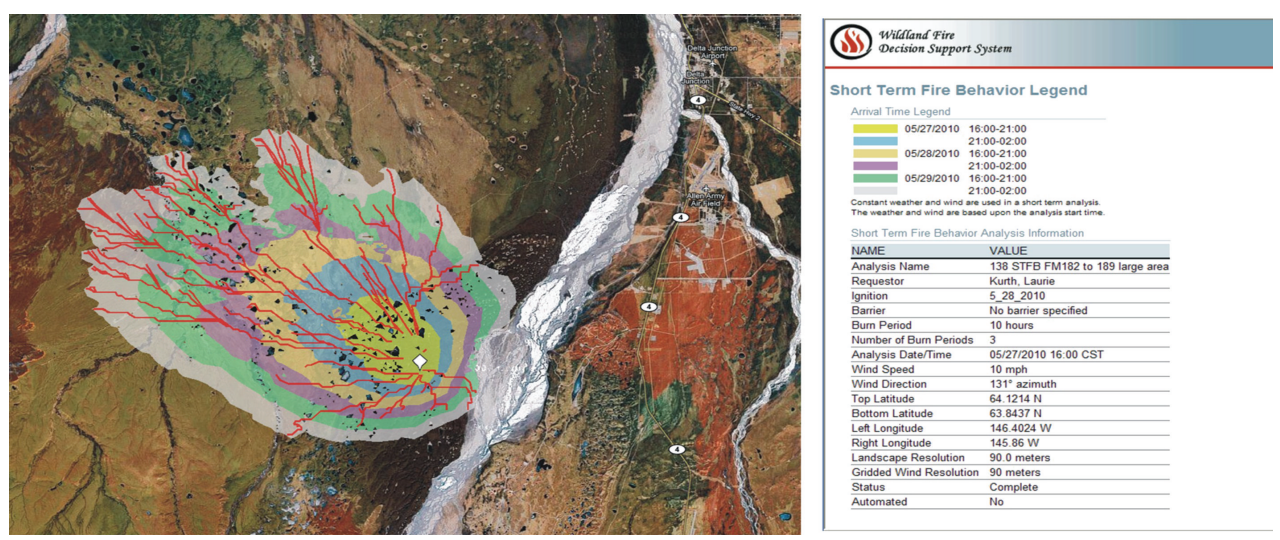

(a)
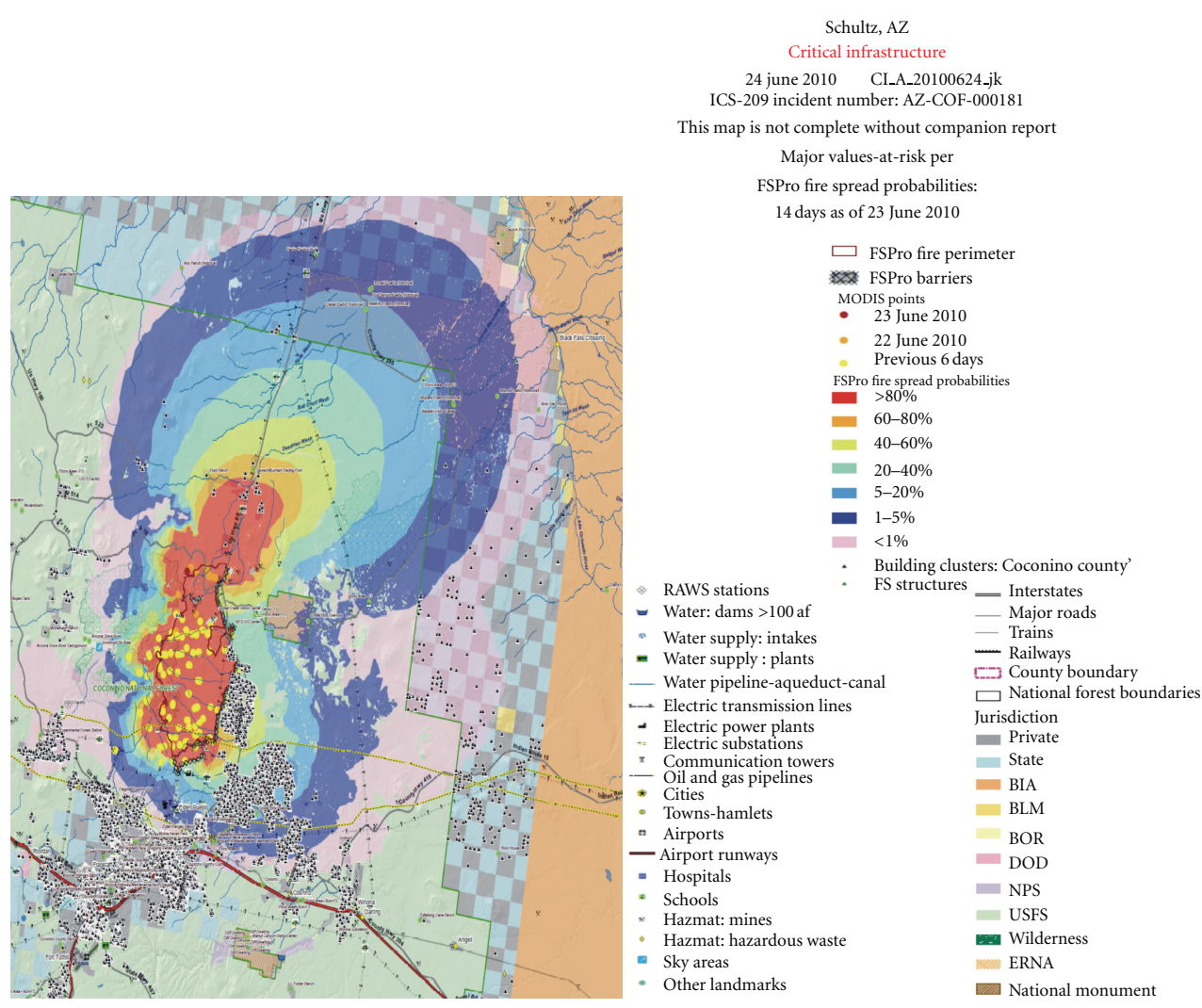

(b)

FIgure 3: (a) Short-term fire behavior results for the Mississippi Impact Area fire in Alaska (AK-MID-000138) from May 2010. The simulation was for three 10-hour burn periods under constant wind and weather conditions. Shaded areas display fire arrival times in 5hour intervals. Red vectors represent the major fire spread pathways based on the minimum travel time (MTT) algorithm [14]. (b) Critical infrastructure intersected with FSPro probabilities [16] for the Schultz fire in Arizona (AZ-COF-000181) from June 2010 illustrates the graphical output associated with a rapid assessment of values at risk (RAVAR). This map displays the probability of fire spread impacting critical infrastructure, such as structures, gas pipelines, and power transmission lines over a 14-day period based on simulating 2000 fires.

overlaid with values at risk. This is referred to as a rapid assessment of values at risk (RAVAR, see Section 3.4.2).

3.4.2. Economics. Economic tools in WFDSS provide managers with an estimated cost of the fire and an assessment of values at risk such as natural resources and infrastructure summarized by probability zones using predictive fire behavior modeling systems.
The stratified cost index (SCI) provides a historical comparison of the costs of a current fire to ones with similar characteristics and potential [17]. Variables such as area burned, fire environment, proximate values, federal agency and geographic region were used to predict the likely costs associated with large wildland fires in the United States. Fire environment includes aspect, slope, fuel type, observed flame length, and the ERC. Values at risk include distance to the 
nearest town, total housing values within a specified distance from the ignition point, and proximity to wilderness areas [17]. Cost estimates are generated by six annually updated equations that vary by location and different land management agencies. Initial model development was completed through the analyses of 1,550 fires exceeding 40.5 ha in size from 1995 to 2004. The SCI model includes eastern and western US models, because fire expenditures in the western US far exceeded those spent in the eastern US [17].

Immediate estimates of values at risk are currently available with the fire behavior tools in WFDSS (shortterm, near-term, and FSPro) [18]. Short-term and nearterm simulations report a simple, qualitative inventory of values within a planning area encompassing the simulated perimeter. FSPro outputs show a values inventory summarized by probability zones as well as the expected quantity of each threatened value. Additionally, wildfire risk and impacts can be quantitatively assessed using the rapid assessment of values at risk (RAVAR) tool. RAVAR couples fire spread probability prediction with geospatial values by quantifying critical infrastructure most likely to be at risk and produces tabular and spatial information that assist fire managers in developing strategies [19] (Figure 3(b)). RAVAR data can be characterized into two groups: (1) critical infrastructure (CI) and (2) natural and cultural resources (NCR). CI includes private structures, water supply systems and reservoirs, major power lines, pipelines, communication towers, recreation facilities, public reserve areas, hazardous waste sites, and other significant landmarks. Private structures are identified using county-level geospatial cadastral data. NCR data reflect highly valued natural and cultural resources and local resource management priorities that may be affected by an ongoing fire event. Examples of NCR layers include sensitive wildlife habitat, recreation zones, culturally significant sites, and restoration priority areas. Due to the importance of applying local expertise to assess wildfire risk to these values, maintenance of these regional and local NCR data within WFDSS is currently being explored.

3.4.3. Air Quality and Emissions. Air quality concerns regarding potential smoke impacts can be addressed through the use of the WFDSS air quality portal, WFDSS-AQ. This portal provides decision makers access to a variety of historic, realtime, and forecasted air quality information using a standalone web portal [20]. Eight air quality and emissions tools provide real-time information about the current smoke situation, climatological statistics, and forecasts. The interactive mapping interface provides locations of current fires and smoke concentrations for the contiguous US once a user sets a fire location manually or links to the tool from a fire location already entered in WFDSS.

Five tools are available for immediate and short-term smoke assessments. Smoke guidance tools provide firespecific tabular point forecasts and regional maps of air quality metrics. The point forecast is a localized textual summary of atmospheric conditions affecting smoke, including mixing height, transport winds, ventilation index, and atmospheric stability (Haines index). The regional map shows predicted atmospheric conditions and smoke concentrations for PM2.5 particulates at ground level in an animated interface for three- or seven-day forecasts. To quickly examine the possible timing and geographic extent of plume impact, managers use the fire information and smoke trajectories tool, which forecast the expected smoke travel path for three starting heights $(500,1000$, and 3000 meters) along the trajectory. The current air quality conditions tool displays real-time particulate or ozone concentrations with a colored air quality index (AQI), representing the potential for health impacts to various groups. Finally, the customized fuels, consumption, and smoke modeling tool provides one location to model fuel loadings, amount and rate of fuel consumption, plume rise, and smoke concentrations visualized on a web browser along with text-based reports.

Three additional tools are available for long-term planning using up to 40 years of climatological data to summarize statistics and graphics for mixing heights, surface winds, and ventilation indices. For both daytime and nighttime periods, the diurnal surface wind pattern analysis tool allows managers to use climatological data derived from a RAWS closest to the fire, to graphically summarize the distribution of wind speeds and directions. The probabilistic smoke impacts based on this past weather tool is meant for advanced modelers with an understanding of statistics. The user defines burn parameters to model probabilistic smoke impacts to forecast what may occur on a fire with similar parameters. Maps show average and maximum impact and percent time above a nationally regulated air quality threshold. To understand the ability of the atmosphere to remove smoke from an area or potential for nighttime smoke drainage, managers use the climatological ventilation index point statistics tool. This tool graphically displays monthly averages of surface wind, mixing height, and ventilation indices across the continental US on five-kilometer grids.

\section{System Architecture}

WFDSS is a J2EE, java server faces (JSF) web application using a service-orientated architecture (SOA). Within this context, WFDSS integrates a number of other technologies in order to store, create, query, and display geospatial and tabular data through the application server as well as other services (Figure 4, Table 3).

The application server handles much of the routine system chores such as creating incidents, displaying tables and map pages, and managing user inputs. To keep the application responsive to the load of hundreds of simultaneous users, tasks that place significant demands on the Application server are passed to other servers running services.

WFDSS consists of a production system and a training system. The production system is used for real fires and the training system provides a platform for training and practice. Both systems share the same hardware and reference data, but have separate databases with information on individual fires and analyses. The workload between the two systems tends to be offset because the production system demand increases during the peak of the western US fire season in summer, while the training system is primarily used during winter and spring months when fire activity is lower. 


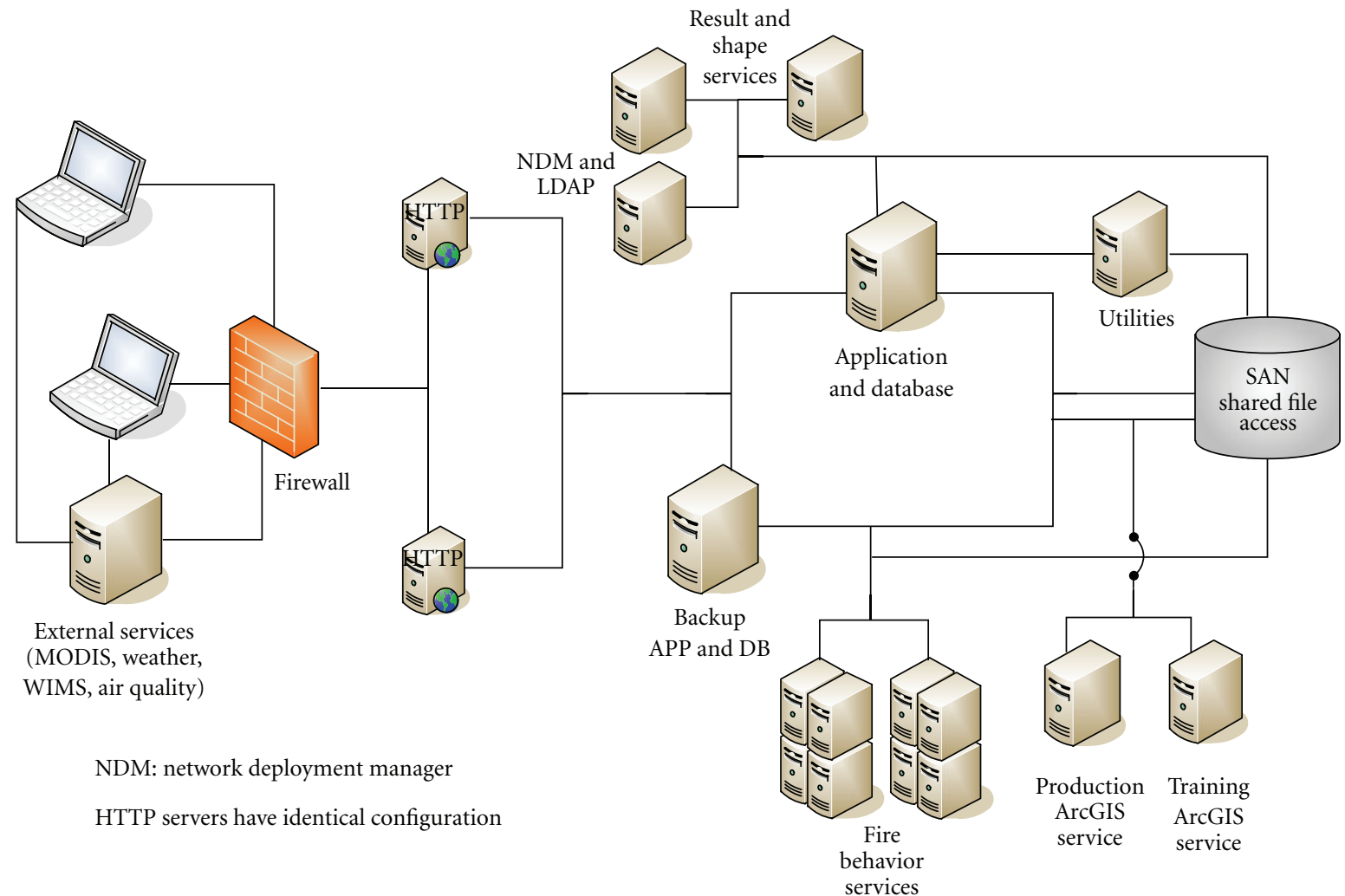

FIGURE 4: WFDSS technical architecture diagram for the production and training systems.

TABLe 3: Specifications of the physical servers shown in Figure 4.

\begin{tabular}{|c|c|c|c|c|c|}
\hline Primary use & Secondary use & Quantity & Processors & RAM & OS \\
\hline $\begin{array}{l}\text { Application/database/ArcSDE } \\
\text { /WebSphere MQ }\end{array}$ & Landscape service & 1 & 4 & $64 \mathrm{~GB}$ & AIX \\
\hline $\begin{array}{l}\text { Backup application/ database/and } \\
\text { so forth }\end{array}$ & & 1 & 2 & $2 \mathrm{~GB}$ & AIX \\
\hline HTTP & & 2 & 8 & $4 \mathrm{~GB}$ & 32-bit Windows \\
\hline LDAP/NDM & $\begin{array}{l}\text { Backup shape and results } \\
\text { services }\end{array}$ & 1 & 8 & $4 \mathrm{~GB}$ & 32-bit Windows \\
\hline LDAP/NDM & & 1 & 8 & $4 \mathrm{~GB}$ & 32-bit Windows \\
\hline Shape and results services & & 1 & 8 & $16 \mathrm{~GB}$ & 32-bit Windows \\
\hline $\begin{array}{l}\text { Fire behavior server-basic, } \\
\text { short-term, and near-term }\end{array}$ & $\begin{array}{l}\text { Image, publish document, } \\
\text { external source, perimeter } \\
\text { download }\end{array}$ & 1 & 8 & $16 \mathrm{~GB}$ & 32-bit Windows \\
\hline Utilities & & 1 & 8 & $16 \mathrm{~GB}$ & 32-bit Windows \\
\hline Production GIS server & $\begin{array}{l}\text { Fire behavior server-basic, } \\
\text { short-term, and near-term }\end{array}$ & 1 & 16 & $32 \mathrm{~GB}$ & 64-bit Windows \\
\hline Training GIS server & $\begin{array}{l}\text { Fire behavior server-basic, } \\
\text { short-term, and near-term }\end{array}$ & 1 & 16 & $32 \mathrm{~GB}$ & 64-bit Windows \\
\hline Fire behavior server-FSPro & & 4 & 32 & $64 \mathrm{~GB}$ & 64-bit Windows \\
\hline $\begin{array}{l}\text { Fire behavior server-basic, } \\
\text { short-term, and near-term }\end{array}$ & $\begin{array}{l}\text { Image, publish document, } \\
\text { external source, perimeter } \\
\text { download }\end{array}$ & $2-6$ & 16 & $32 \mathrm{~GB}$ & 64-bit Windows \\
\hline
\end{tabular}


TABLE 4: List of WFDSS internal services.

\begin{tabular}{ll}
\hline Service name & Purpose \\
\hline Basic & Basic fire behavior modeling system \\
FSPro & FSPro fire behavior modeling system \\
Near-term & Near-term fire behavior modeling system \\
Short-term & Short-term fire behavior modeling system \\
Landscape & Landscape file creation \\
Publish document & Creation of HTML and PDF documents for download \\
External source & Computer aided dispatch batch upload service \\
& Screen captures of WFDSS map pages, fire behavior characteristic \\
Image & raster/legend creation, landscape attribute raster/legend creation, values \\
& inventory/values at risk \\
Perimeter download & Fire perimeter download service \\
Results & Processes FSPro, near-term, and short-term results to create shape files \\
Shape & Uploading of shape files (requires WinZip) \\
\hline
\end{tabular}

TABLE 5: List of WFDSS external services.

\begin{tabular}{ll}
\hline External Service & Purpose \\
\hline Fire weather forecast & $\begin{array}{l}\text { Text-based fire weather forecasts from the National Weather Service, } \\
\text { included in all decisions } \\
\text { Gridded seven-day digital forecast from the National Weather Service, used } \\
\text { for fire behavior modeling and forecasted fire danger }\end{array}$ \\
Weather information management system (WIMS) & $\begin{array}{l}\text { Data from remote automated weather stations (RAWS) used for historic } \\
\text { fire danger and fire behavior modeling inputs }\end{array}$ \\
WODIS & $\begin{array}{l}\text { Web mapping service of MODIS infrared signal available on all WFDSS } \\
\text { maps }\end{array}$ \\
Air quality tools & Air quality forecasts from a variety of sources \\
\hline
\end{tabular}

4.1. Internal Services. Much of the computationally demanding workload, such as fire behavior analyses or image tile generation, is handled via internal services as described in Table 4. Communication between the application server and the services, as well as between other services, is accomplished through a messaging service (JMS). The application server (or other service) simply puts a message on the queue for a specific service and the individual services monitor the queue. This allows the system to expand easily by adding new hardware and services without modifying the application server.

4.2. External Services. While some of the large datasets used by WFDSS are mirrored internally (such as LANDFIRE) for performance reasons, other dynamic data and information are automatically acquired on a regular schedule or as needed. External services currently used by WFDSS are described in Table 5.

4.3. Authentication. Both systems use a lightweight directory access protocol (LDAP) to authenticate users. Per US federal security requirements, all WFDSS users with accounts must complete annual information technology security awareness training. This training is required of federal and non-federal employees and contractors.
Users with federal agency email accounts are automatically given the viewer (read-only) role for both training and production systems because maintaining a federal email account requires the annual security training. Other users are given access only after being vetted by a user with administrative authority to ensure there is a business need to access the system and to validate compliance with the security training requirements. Within the application, users have roles (system wide) and privileges (incident/analysis level). These roles can be different between training and production. Roles are assigned as needed by administrative authorities, while incident and analysis privileges are given by the incident owner.

\section{WFDSS Operation and Implementation}

5.1. Usage Statistics. Since the operational use of WFDSS began in 2007, WFDSS has experienced a steady increase of decision and analytical support (Figure 6). From 2007 to 2010, the number of incidents recorded annually in WFDSS increased from 218 to 12,433 . This increase corresponded with the national 2009 policy, which directed that every wildland fire be assessed using a single decision support process [3]. Although federal agencies implemented the use of WFDSS differently, most agencies used the system 


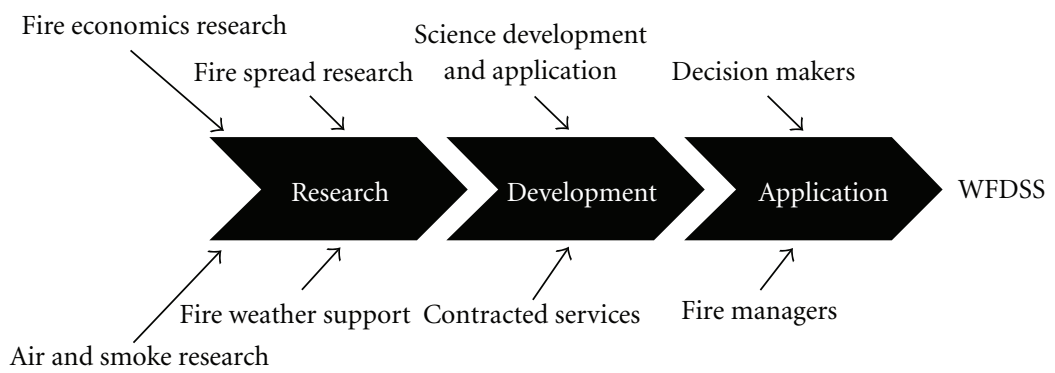

FIGURE 5: Schematic of personnel involved in the research, development, and application of WFDSS.

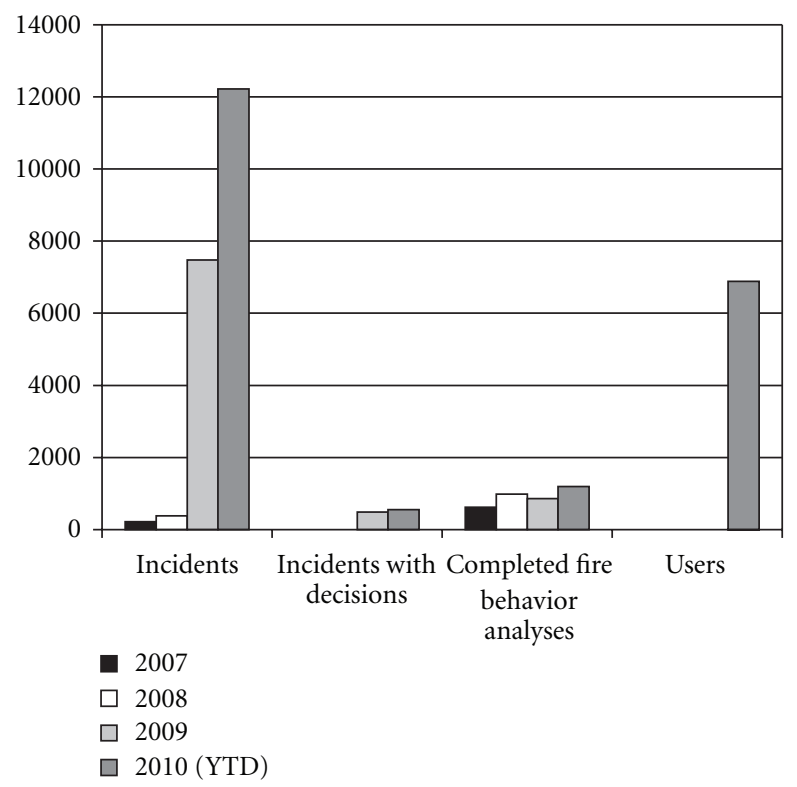

FIgURE 6: Usage statistics from 2007 to 2010 (YTD). Year to date includes data through November 20, 2010.

for fire documentation in 2010. "Incidents with decisions" required a formal decision be published based on increasing fire complexity. This value was tracked for the 2009 and 2010 fire seasons and increased slightly from 491 to 550 incidents with a published decision, reflecting greater agency usage of WFDSS for wildland fire decision documentation in 2010 compared to 2009. As more fire managers applied WFDSS for decision support, the number of completed fire behavior analyses also increased from 619 in 2007 to 1195 in 2010, with a slight decrease in 2009, likely due to a milder national fire season. Completed fire behavior analyses include all basic, short-term, near-term, and FSPro fire behavior analyses that were accepted by a fire manager and assisted with decision-making. Finally, data regarding the number of fire-related managers and professionals with an authorized WFDSS logon (users) was not tracked until 2010. Currently, there are close to 7,000 users within WFDSS.

5.2. Personnel. The research, development, and application phases of WFDSS involve numerous personnel including researchers, internet technology contractors and programmers, and fire managers (Figure 5). The basis for the WFDSS prototype was developed by Forest Service Research while the actual application was a result of an integrated effort between Forest Service Research and Fire and Aviation Management. Current WFDSS development and operation is managed by the Forest Service Wildland Fire Management Research, Development, and Application Program with support from other federal land management agencies. This includes oversight of the technical development and programming of WFDSS by contracted professionals from private industry. As WFDSS evolves, air quality, fire weather, fire behavior, economic, risk assessment, decision science, and fire ecology researchers are developing additional decision support tools. These processes are migrated into WFDSS for operational use via development and support personnel. These professionals, possessing an operational fire background, test the initial research concepts, coordinate with programmers and IT contractors, and release new user versions after making program revisions and enhancements. Full implementation and application in wildland fire decision-making is 
accomplished by fire managers and other associated decision makers during live fire situations.

\section{Conclusion}

WFDSS will continue to evolve and incorporate newer research models and technology advancements. Potential areas of improvement and development include pre- and post-ignition decision-making and documentation, and system responsiveness to user requests. While currently applied as an operational wildland fire decision support system, many of the systems embedded in WFDSS could be used for pre-ignition decision-making including optimization and placement of fuel treatments. The development of a fuel treatment decision support system is already underway and similar to the conceptual architecture of WFDSS [21]. Improvements with post-ignition decision-making are also being developed as the decision-making process becomes more succinct. This potentially includes a national database establishment that stores consistent formats of geospatial information, fire summary statistics, and strategic and tactical knowledge. The quantification of risk for both infrastructure and natural resources is an emerging field for fire economics. Building on the existing WFDSS framework, a newer approach to risk quantification may include updated methods to better quantify risk for natural resources [22]. System improvements, such as the speed of data acquisition and transmission capabilities, are another area of improved focus for the future. Future implementation could involve an expansion to a much larger user set, if state and local agencies decide to use WFDSS for decision support, decision documentation, and implementation planning.

Management of wildland fire represents one of the most complex and highest risk activities in natural resource management. Decision support information reduces uncertainty surrounding a wildland fire, allows decision makers to understand management challenges and potential outcomes, and helps frame selection of desired strategies and operational tactics. Decision support is gained by combining fire research and modeling with ecological, economic, and social considerations to produce a situational analysis and risk assessment, and then by connecting decisions to land and resource management objectives. A progressive and swift decision documentation and analysis process that allows immediate response to changing situations or scale represents significant improvements to the entire fire management decision-making process. This process, the kind and amount of information, and the speed that it can be acquired, analyzed, and utilized was not possible before WFDSS. WFDSS is unique when compared to all previous fire decision analysis and documentation systems in the US and is an important step in the process of modernizing situational analysis, risk assessment, and complex decision-making.

\section{Acknowledgments}

The creation and overall success of WFDSS were made possible by the contributions from organizational funding and many individuals. The authors are indebted to visionaries like John Szymoniak and programmers such as Stu Brittain. The enthusiasm and dedication of the development team at IBM along with many field testers, users, and evaluators were instrumental in the creation and development of WFDSS. Funding for WFDSS was provided primarily by the USDA Forest Service Fire and Aviation Management, State and Private Forestry, and the Department of Interior Office of Wildland Fire Coordination. Contributing staff and associated work accomplishments by the Department of Interior Bureau of Indian Affairs, National Park Service, and Office of Wildland Fire Coordination also contributed to the implementation of WFDSS.

\section{References}

[1] D. E. Calkin, K. M. Gebert, J. G. Jones, and R. P. Neilson, "Forest service large fire area burned and suppression expenditure trends, 1970-2002," Journal of Forestry, vol. 103, no. 4, pp. 179-183, 2005.

[2] S. L. Stephens and L. W. Ruth, "Federal forest-fire policy in the United States," Ecological Applications, vol. 15, no. 2, pp. 532-542, 2005.

[3] USDA-USDI, "Guidance for Implementation of Federal Wildland Fire Management Policy (February 2009)," U.S. Department of Agriculture, U.S. Department of Interior, Boise, Idaho, USA, 2009 http://www.nifc.gov/policies.htm.

[4] USDI-USDA, Federal Wildland Fire Management and Policy and Program Review, U.S. Department of Interior, Bureau of Land Management, Boise, Idaho, USA, 1995.

[5] NWCG, Review and Update of the 1995 Federal Wildland Fire Management Policy, National Interagency Fire Center, Boise, Idaho, USA, 2001.

[6] NWCG, "Update on the modifications to the interagency strategy for the implementation of Federal Wildland Fire Management Policy," Memorandum NWCG \#001-2009, National Wildfire Coordinating Group, Boise, Idaho, USA, 2009.

[7] NFAEB, Wildland Fire Decision Support System Charter, National Fire and Aviation Executive Board, Wildland Fire Management Research, Development, and Application Program, Boise, Idaho, USA, 2005.

[8] USFS-USDOI, “LANDFIRE," U.S. Department of Agriculture Forest Service-U.S. Department of Interior, 2010, http://www.landfire.gov/index.php.

[9] J. E. Deeming, R. E. Burgan, and J. D. Cohen, "The national fire-danger rating system-1978," General Technical Report INT-39, U.S. Department of Agriculture, Forest Service, Intermountain Forest and Range Experiment Station, 1977.

[10] R. C. Rothermel, "A mathematical model for predicting fire spread in wildland fuels," Research Paper INT-115, U.S. Department of Agriculture, Forest Service, Intermountain Forest and Range Experiment Station, 1972.

[11] R. C. Rothermel, "Predicting behavior and size of crown fires in the northern Rocky Mountains," Research Paper INT-438, U.S. Department of Agriculture, Forest Service, Intermountain Forest and Range Experiment Station, 1991.

[12] C. E. Van Wagner, "Conditions for the start and spread of crown fire," Canadian Journal of Forest Research, vol. 7, no. 1, pp. 23-34, 1977.

[13] F. A. Albini, "Spot fire distance from burning trees-a predictive model," General Technical Report INT-56, U.S. Department of Agriculture, Forest Service, 1979. 
[14] M. A. Finney, "Fire growth using minimum travel time methods," Canadian Journal of Forest Research, vol. 32, no. 8, pp. 1420-1424, 2002.

[15] M. A. Finney, "FARSITE: Fire Area Simulator-model development and evaluation," Research Paper RMRS-RP-4, U.S. Department of Agriculture, Forest Service, 1998.

[16] M. A. Finney, I. C. Grenfell, C. W. McHugh et al., "A Method for Ensemble Wildland Fire Simulation ," Environmental Modeling and Assessment, vol. 16, no. 2, pp. 153-167, 2011.

[17] K. M. Gebert, D. E. Calkin, and J. Yoder, "Estimating suppression expenditures for individual large wildland fires," Western Journal of Applied Forestry, vol. 22, no. 3, pp. 188-196, 2007.

[18] R. C. Seli, J. R Fiedler, and D. E. Calkin, "Coupling fire behavior models with other decision support tools," in Proceedings of the 6th International Conference on Forest Fire Research, D. X. Viegas, Ed., Association for the Development of Industrial Aerodynamics, Coimbra, Portugal, November 2010, (CD-ROM).

[19] D. E. Calkin, M. P. Thompson, M. A. Finney, and K. D. Hyde, "A real-time risk-assessment tool supporting wildland fire decision-making," Journal of Forestry. In press.

[20] N. S. Larkin, T. Brown, P. Lahm, and G. T. Zimmerman, "Wildland fire decision support system air quality tools," Fire Management Today, vol. 70, no. 2, pp. 36-40, 2010.

[21] G. Wells, "A powerful new planning environment for fuels managers: the interagency fuels treatment decision support system," Fire Science Digest, vol. 7, pp. 1-12, 2009.

[22] M. A. Finney, "The challenge of quantitative risk analysis for wildland fire," Forest Ecology and Management, vol. 211, no. 1-2, pp. 97-108, 2005. 

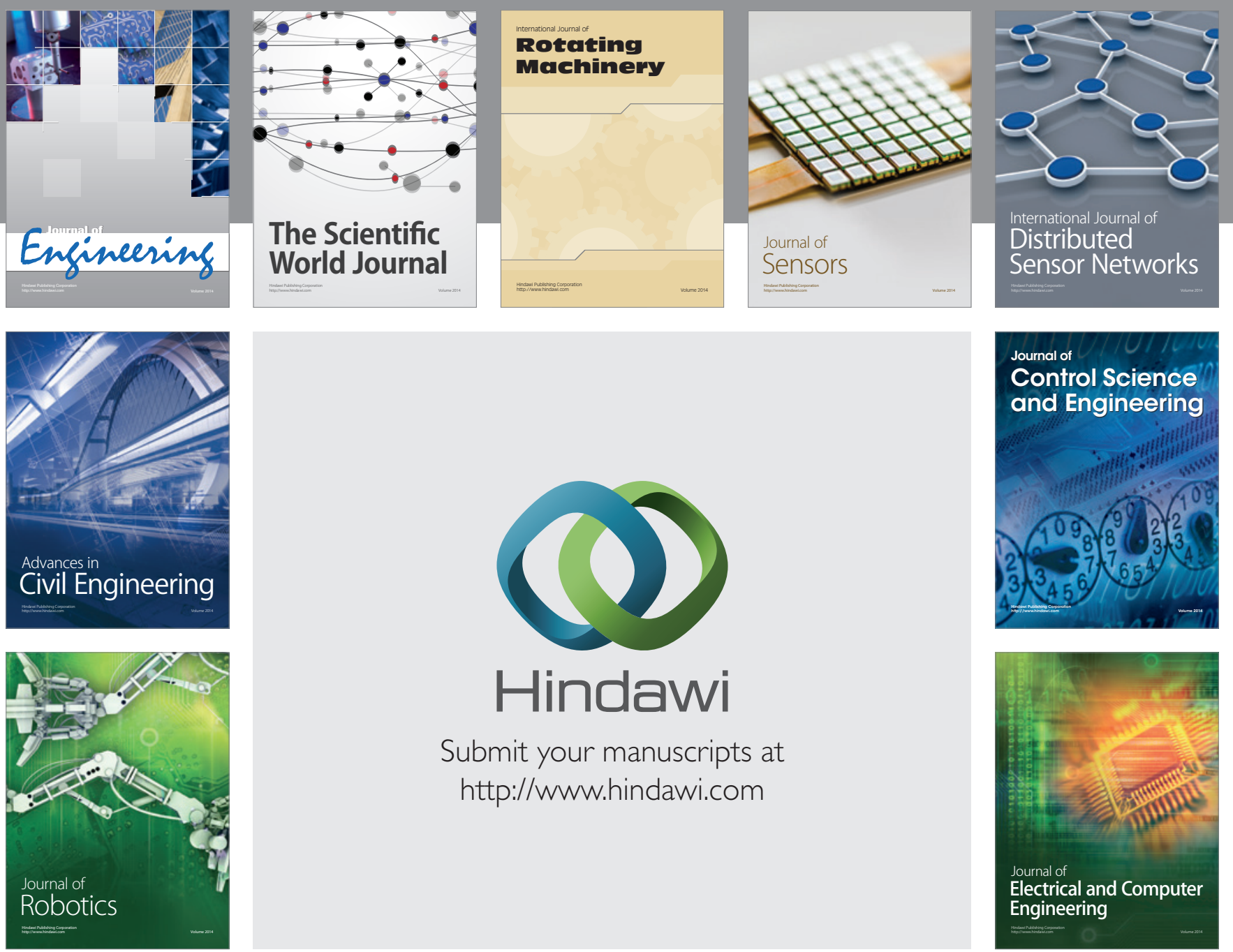

Submit your manuscripts at

http://www.hindawi.com
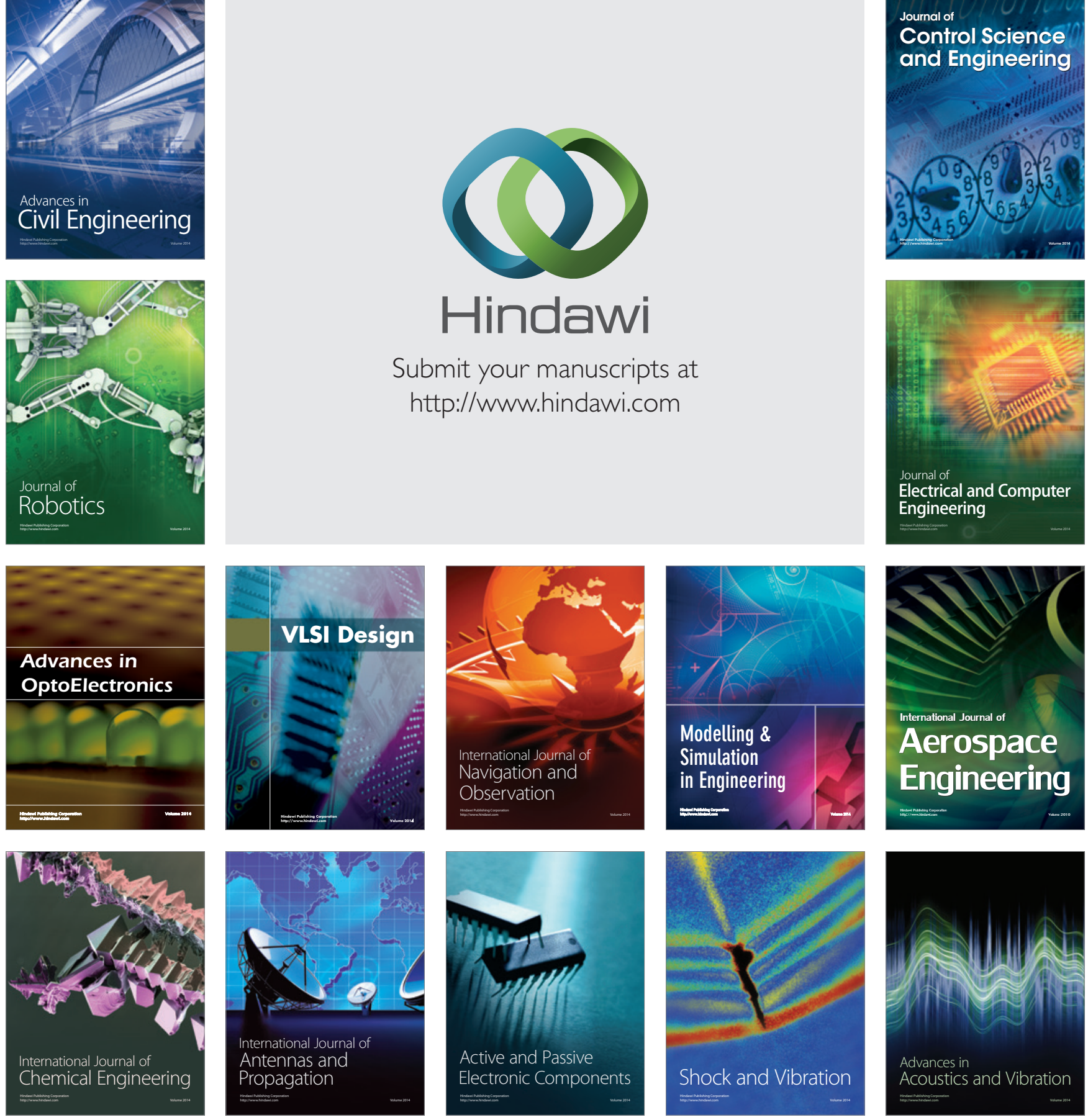